\title{
FEASIBILITY STUDY OF SWINE MANURE MANAGEMENT ON RECLAIMED SURFACE MINE LANDS ${ }^{1}$
}

\author{
by
}

\author{
Emest F. Bazen, Ronald A. Fleming, and Stephen R. Workman ${ }^{2}$
}

\begin{abstract}
Initial results are presented of a decision model that addresses issues associated with the siting of swine production facilities on Kentucky's reclaimed surface mine lands. Issues relating to swine manure management have received much attention from state governmental and environmental regulatory authorities. Specifically, the state is concerned about nutrient and fecal contamination of surface and ground water while the public is concemed primarily with odor control. Mine reclaimed lands represent remote areas where swine production facilities can be located without the concern about odor nuisance. Furthermore, reclaimed soils can substantially benefit from manure nutrients. The purpose of this research is to evaluate swine manure management strategies to determine what strategy or set of strategies jointly minimize groundwater contamination and production cost. To achieve the objectives of this research, the computer simulation model (OPUS) was used to estimate the rate of soil water flow as well as the eventual fate and concentration of nitrate-nitrogen and other nutrients in soil water. These nutrient concentrations will be used to assess the environmental impact of alternative swine manure systems. Environmental, economic, and social impacts associated with various waste management options are described that help to achieve a better waste management strategy. A quick demonstration of the OPUS model is presented. Initial results suggests that nitrate-nitrogen uptake and sediment flow rates can be closely estimated on reclaimed surface mine land soils that are characterized by a single soil profile.
\end{abstract}

Additional Key Words: simulation, pollution, hydrology, soil water, transport

\section{Introduction}

Evaluating the relationship between swine manure best management practices and groundwater quality on reclaimed surface mime land has brought about a new challenge to the state of Kentucky. The environmental impacts from livestock manure and the nutrients they contain continue to be a concem

${ }^{1}$ Paper presented at the 2000 National Meeting of the American Society for Surface Mining and Reclamation, Tampa, Florida, June 11-15, 2000.

${ }^{2}$ Emest F. Bazen is Associate Researcher Department of Agricultural Economics, University of Kentucky, Lexington, KY 40546; Ronald A. Fleming is Assistant Professor of Agricultural Economics, University of Kentucky, Lexington, KY 40546; and Stephen R. Workman is Assistant Professor of Biosystems and Agricultural Engineering, University of Kentucky, Lexington, KY 40546. within rural Kentucky. Learning how to better manage manure storage and treatment has become important to both researchers and public alike. The increasing environmental problems and policy debates surrounding the manure produced at concentrated livestock production facilities, new ways of managing manure (Christensen, 1999).

In particular, agriculture's contribution to water quality problems is receiving increased attention from policy-makers and other interest groups. In 1997, the swine inventory stood at 60 million head, and the figure has climbed $18 \%$ over the past decade. During the same period, the number of swine farms dropped by $72 \%$. The largest farms have grown larger, resulting in less than $1 \%$ of farms (with at least 2,000 animals) accounting for $43 \%$ of the inventory. Farms with an inventory of at least 1,000 head represent less than $3 \%$ of all U.S. farms, but $60 \%$ of the swine are produced on them. The remaining $97 \%$ of the farms (raising fewer than 1,000 head) produce only $40 \%$ of the U.S. inventory. Perhaps more important, states with rapid growth in overall herd size have higher portions of their herds in very large operations. For example, almost $80 \%$ of swine sales in North Carolina, South Carolina, and

Proceedings America Society of Mining and Reclamation, 2000 pp 620-626

DOI : $10.21000 /$ JASMR00010620 
Virginia are from operations with at least 5,000 head, compared to only $16 \%$ of sales in traditional producing areas (Copeland \& Zinn, 1998).

Manure can no longer be considered an innocent by-product of livestock production. Instead of something to be disposed in the easiest manner or perhaps used for its nutrient content and contributions to soil quality, the concentration of livestock production into larger units has caused increased public outcries over "mountains" of manure that are perceived to be causing water pollution and noxious odors.

Several water quality models for agricultural field studies are available. These include CREAMS (Chemicals Runoff and Erosion from Agricultural Management Systems (USDA-ARS, 1980)), EPIC Erosion Productivity Indicator Calculator (Sharpley and Williams, 1990; Williams et al., 1990), GLEAMS (Groundwater Loading Effects of Agricultural Management Systems) (Leonard et al., 1987), and Opus (Smith, 1992). All of these models have been utilized in research and could have been chosen for this study. Several criteria for choosing one specific hydrologic model over another were outlined by Haan et al. (1994): type of problem, available documentation, characteristics, and user modeling experience.

Opus was the model chosen for this study. Smith (1992) claimed that Opus is a substantial improvement over other models in its simulation of water movement and chemical transport. Smith and Ferreira (1989) demonstrated the ability of Opus to improve upon many points that other models inadequately simulated. Their study compared three competitive models, GLEAMS, SHAW, and NTRM (Nitrogen, Tillage, and crop-Residue Management) (Shaffer and Larsen, 1987). Opus predictions were accurate for the runoff rate from a measuring flume. Opus appeared to be better for this study because of its advantages over the other models in its flexible time step selection and in the treatment of interblock hydraulic conductivity of the soil. The $2.1 \mathrm{e}$ version (March 31, 1999) of Opus was used in this study. The purpose of this research is to evaluate swine manure management strategies to determine what strategy or set of strategies jointly minimize groundwater contamination and production cost.

\section{Opus Model}

Opus is a computer simulation model that describes water flow, hence the transport of pollutants in soils. It is agriculturally focused and formulated to estimate the relative effects of different management practices on nonpoint-source pollution from field-sized areas. Developed within the United States Department of Agriculture (USDA) Agricultural Research Service at the end of the 1980 's, the primary objectives were similar to the GLEAMS and CREAMS models.

Like other comprehensive hydrologic models published for public use, Opus represents a snap-shot of current scientific understanding of natural processes and practical constraints, especially the limits of available user data. Opus attempts to use modern soil physics to describe the movement of soil water, and attempts to closely integrate many processes that relate to hydrology and interact with each other. Opus is designed to study the effects of agricultural management practices, such as irrigation, tillage, fertilizer distribution, and pesticide distribution on the environment (Pierson et al., 1992). The platform of the model is based on Richards equation (Richards, 1931), which describes one-dimensional, unsaturated flow through a soil profile, based on Darcy's law and the continuity equation (Haan et al., 1994). An iterative method is used by Opus to solve the Richards equation.

The creation of Opus brought together a number of existing models by adapting their successful parts and blending and expanding upon them (Smith, 1992). The daily weather generation module was obtained from the WGEN model developed by Richardson (1981). The evaporation and evapotranspiration module incorporated into Opus was developed by Ritchie (1972) and is used by EPIC and CREAMS models. The daily runoff module in Opus (Smith and Williams, 1980) is used by EPIC and SWRB. The soil erosion section of Opus was taken from MUSLE (Williams and Berndt, 1977).

Where ever possible, default values or tables of suggested parameter values are provided. This allows the use of the model in the absence of measured data. This includes the difficult-to-measure soil hydraulic parameters and a range of typical parameters for the crop growth model. Data can be input in either English or metric units, and the output also reported in either unit system. The computer program operates internally in the metric system.

As the hydrologic processes are simulated, the model can simultaneously simulate several other optional, interactive processes. These include erosion 
and sediment transport, and the application and transport of pesticides and fertilizers. Opus can also simulate the various transformations in the soil organic system, including residue decay and the carbon, nitrogen, and phosphorus cycles. Other optional processes that Opus can simulate include irrigation, drainage controls, and small farm ponds.

\section{Methodology}

Following the collection of relevant data, efforts turned to the parameterization of Opus: Using information provided in the manuals, missing parameter values were identified. An area in Muhlenburg County, Kentucky was selected as the test site. A continuous corn rotation with no-till management was the management system. No fertilizer or pesticides were used. Liquid swine manure was the sole plant nutrient source utilized in this scenario.

For any simulation, the Opus model requires specification of the weather and rainfall pattern and also a basic description of surface and subsurface soil features. A complete list of Opus inputs required to perform a simulation are given in the User Manuals Volumes I \& II (Smith, 1992).

Three separate files of information are utilized by Opus. A parameter input file contains information pertaining to the soil horizons, the crops, the agricultural management techniques performed, the topology of the plot, and a small amount of information about erosion. The second file includes the meteorological data. A third file, which is optional, called the actual data file, can be used to better estimate runoff rates or erosion measurements if available. This file option was not used for this study.

Information relating to the agricultural management practices/techniques and topography were found in the literature and previous research studies performed by Ward (1981). In addition, inputs were also gathered from simple observation in the field or from analyses performed in laboratories at the University of Kentucky. Not all information was readily available. In those instances where experimental data was not available, the Opus manuals were relied upon to estimate those parameter values. Weather data were provided by the Spindletop weather station of the University of Kentucky.
In all cases, the Opus model simulates runoff and soil water inputs and redistribution. The parameter file template is divided into 7 groups (A G). Input group A identifies the simulation beginning and end dates and determines which input, output, and simulation options are to be used. The beginning date chosen for this study was January 01, 1988 and ending on December 31, 1997. Opus offers several output options. The modeler can chose from a detailed day by day output or can use data from summarized monthly and/or annual output reports. The standard output is automatically generated and includes summary information concerming soil hydrologic parameters, such as total seepage, runoff, evapotranspiration, sediment accumulation, nitrate leaching, runoff, and description of crops (daily mass of the crop dry matter).

Group B parameter values include general state and initial conditions of the field. The field size used for this study was 16.2 hectares (40 acres). Some of the variables in this group, such as rainfall $\mathrm{pH}$, typical or annual mean concentration of nitrogen in natural rainwater, evapotranspiration wind value, and initial side slope of field furrows, were set at default values from the manual. The depth of furrows, maximum depth of tillage, mean row spacing of furrows, and all remaining values were determined through observed farm practices and gathered data.

Soil horizon data are the focus of group C parameter values. Selected parameter values used in the simulation process are presented in Table 1. For comparison, an additional column representing Opus manual values is also shown in Table 1 . The soil profile at the research site was assumed to be similar to the data obtained from McIntosh (1988). The soil profile was divided into three layers, with respective depth from the surface being 450,1100 , and 1500 $\mathrm{mm}$. The textural classification of the soil profile was estimated by percentages of clay, silt, and sand within each layer. Also the porosity of each layer was taken from observed data. The saturated hydraulic conductivity parameter of each layer was estimated from similar soil test data from the region.

In addition to the saturated hydraulic conductivity value, Opus requires other hydraulic property values of the soil: bubble pressure, poresize distribution index, and volumetric water content at 15 bars of matric capillary tensions. Table 2 lists the experimental values used for saturated hydraulic conductivity and the volumetric water content at 15 bars of capillary tension and the comparison Opus manual values. The Campbell model is used in cases 
where the relative water content saturation is given as a function of the capillary suction on logarithmic scales (Figure 1). The slope of the linear portion of the curve is equal to the pore-size distribution index (ALAM). The bubbling pressure (PBUB) is equal to the value of the capillary suction where the extrapolation of the linear portion of the curves intercepts the relative saturation line at 1. The volumetric water content at 15 bars matric capillary tension was determined using data measured for the water retention curve. Default values were used for the remaining values that included: the organic carbon (ORGC), organic nitrogen (OMN), and nitrate-nitrogen (WNO3) contents.

Group D of the parameter file describes crops grown during the rotation cycle. Corn was the crop for this study. The parameter values in this category include: maximum leaf-area for the specified crop (PLAI), degree days between planting and emergence (DDEM), degree-day measured from the planting of the crop to its maturity (DDMX), potential total dry matter for the crop (PDRYM), potential yield of fruit and seed of the crop (POTY), potential maximum root depth for plant (RDP), potential total plant height of the plant (POTHT), relative amount of ground surface covered by projected area of the crop (PPCV), minimum temperature for growth of the plant (TGBM), and temperature at which the plant grows at its maximum rate (TGOP). Values from the User's Manual and from Hanks and Ritchie (1991) were used.

The management data are represented in Input operations (including planting and harvests); applications of fertilizers, pesticides, and manure; and irrigation (Ferreira and Smith, 1992). The values and dates chosen for this study were obtained from farming activities in the surrounding plot area. The planting date chosen for this simulation was April 01 with harvesting occurring on October 31 . The manure application for each year was designated on March 25. The values for the manure content (nitrogen, ammonia, phosphorus, and organic matter) were estimated from data obtained from a 5,000 head confined swine facility operation.

Group F describes the dimensions and slope of the catchment as interpreted for hydrologic purposes. Opus allows the user to construct the total field hydraulic geometry with multiples of a simple unit. This feature allows the description of more complex field shapes, such as fields with divided flow and, particularly, terrace systems (Smith, 1992). A slope of 6 degrees was used in the simulation of this study. The final category, group $G$, includes parameter values describing sediment and erosion data.

\section{$\underline{\text { Summary }}$}

The primary purpose of this investigation was to assess the potential siting of Confined Animal Feeding Operations (CAFO's). More specifically, this paper evaluates the potential of swine production on Kentucky's reclaimed surface mine lands. With the rapid growth of CAFO's, the state of Kentucky,

TABLE 1: Selected Parameter File Data

\begin{tabular}{|c|c|c|c|c|c|c|c|}
\hline \multirow{3}{*}{$\begin{array}{l}\text { Horizon } \\
\text { Depth } \\
\text { - (mm) - }\end{array}$} & \multirow{2}{*}{\multicolumn{3}{|c|}{$\begin{array}{l}\text { Soil Texture } \\
\text { Percentages }\end{array}$}} & \multicolumn{2}{|c|}{ Porosity } & \multicolumn{2}{|c|}{ Bubble Pressure } \\
\hline & & & & \multirow{2}{*}{$\begin{array}{l}\text { Experimental } \\
\text { Value }\end{array}$} & \multirow{2}{*}{$\begin{array}{c}\text { Opus } \\
\text { Manual }\end{array}$} & \multirow{2}{*}{$\begin{array}{c}\text { Experimental } \\
\text { Value }\end{array}$} & \multirow{2}{*}{$\begin{array}{c}\text { Opus } \\
\text { Manual }\end{array}$} \\
\hline & Clay & Silt & Sand & & & & \\
\hline $0-450$ & 30 & 35 & 35 & 0.409 & $0.409-0.519$ & 565.7 & 564.3 \\
\hline $450-1100$ & 50 & 30 & 20 & $0.53 \mathrm{I}$ & $0.425-0.533$ & 865.2 & 765.4 \\
\hline $1100-1500$ & 50 & 25 & 25 & 0.550 & $0.425-0.533$ & 2.1 & 856 \\
\hline
\end{tabular}

group E. These data contain: (a) descriptive parameters for all management operations performed and substances applied, and (b) a schedule designating target dates when the various operations are to be performed. The schedule includes tillage as well as many other states, is faced with issues concerning the environmental impacts that these agribusinesses bring with them and not just the positive revenues that their economies will reap. Reclaimed surface mine lands pose interesting 
Figure 1: Water Retention Curve

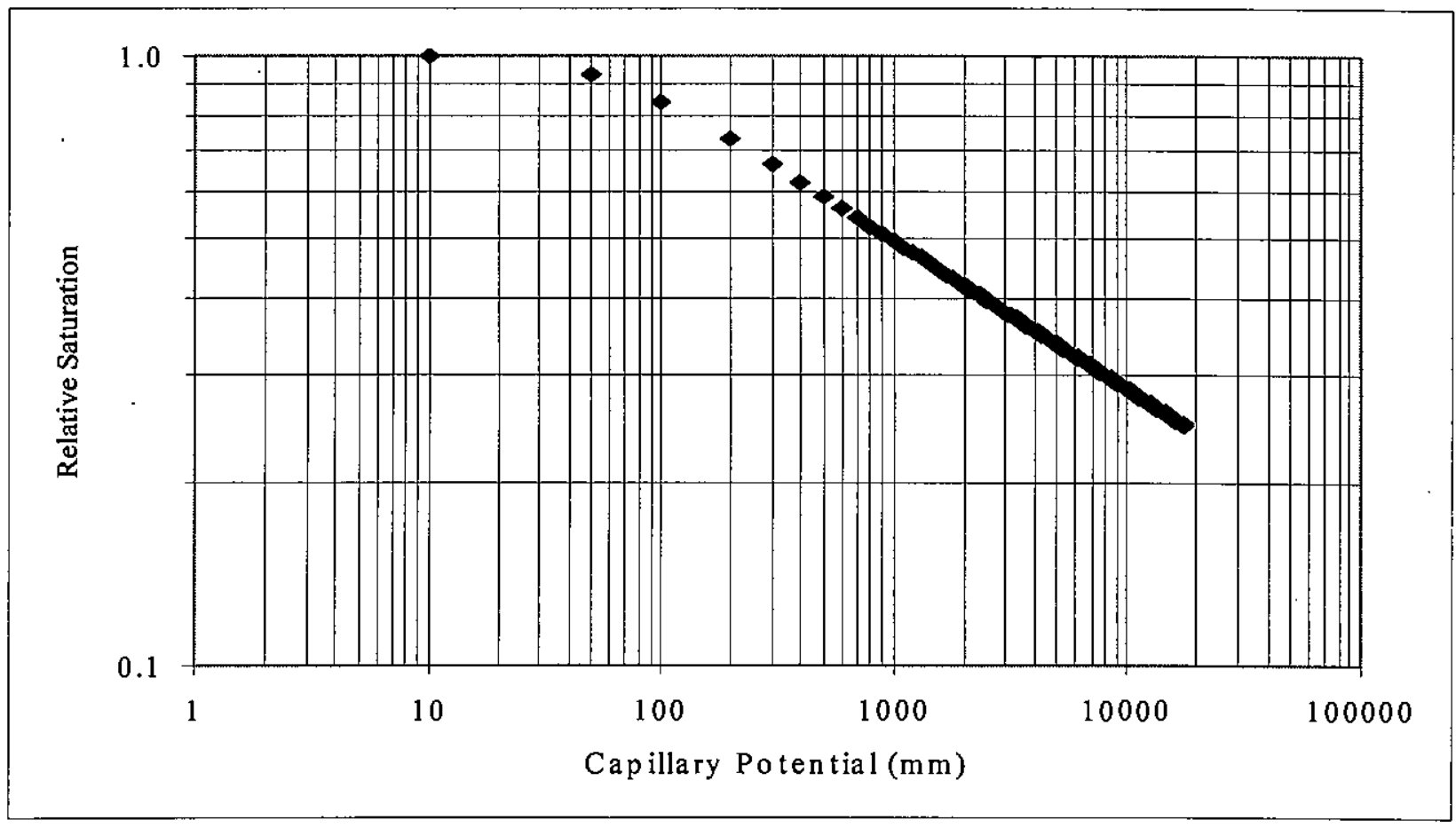

characteristics and a potential solution to many of the current issues related to odor and nuisance which have prompted many states to adopt setback legislation. However, because of fears related to changes in soil structure that increases the perceived risk of catastrophic groundwater contamination, Kentucky environmental authorities are cautious concerning the issuance of permits to produce hogs on and apply manure to mine reclaimed lands.

The disturbed soils of reclaimed surface mine lands have been depleted of many nutrients needed for crop production. Depending on the management system, swine manure may include: animal excrement (including urine), wastewater, spilled feed, open feedlot runoff and bedding. This manure contains considerable amounts of nitrogen $(N)$, phosphorus ( $\mathrm{P}$ ), and potassium $(\mathrm{K})$ and other minerals. These minerals are available for recycling through the soil as plant nutrients. In addition, manure applications improve soil structure, tilth and other soil properties.

Regardless of the collection, storage, treatment, and handling methods used for swine manure, some end products remain. While the simulation of interaction between crop production and swine manure application on Kentucky's reclaimed surface mine lands require further refinement, it appears that simulation using the Opus model allows a reasonable representation of the sediment and nitrate-nitrogen flow rates in reclaimed surface mined soils. The initial model prediction of the monthly and total nitrate-nitrogen leaching and the monthly seepage volume was sufficient to create groundwater contamination. The predicted annual amounts of nitrate-nitrogen leached ranged from 0.01 to 52.15 kilograms per hectare while the seepage volumes ranged from 64.58 to $243.32 \mathrm{~mm}$ annually. This is a significant finding because it provides evidence that swine production would create groundwater

TABLE 2: Selected Parameter Values

\begin{tabular}{|c|cc|cc|}
\hline Horizon & \multicolumn{2}{|c|}{ Satyrated Hydraulic Conductivity } & \multicolumn{2}{|c|}{ Volumetric Water Content at 15 bars of Capillary Tension } \\
\cline { 2 - 5 } Depth & Experimental & Opus & Experimental & Opus \\
$-(\mathrm{mm})-$ & Value & Manual & Value & Manual \\
\hline $0-450$ & 2.3 & 2.3 & 0.147 & 0.148 \\
$450-1100$ & 0.6 & 0.9 & 0.222 & 0.239 \\
$1100-1500$ & 0.1 & 0.6 & 0.045 & 0.272 \\
\hline
\end{tabular}


contamination on these disturbed soils.

These findings are conditional on the simplifying assumptions of this simulation model. Further study is warranted to assess actual field data. A more comprehensive study should include multiple crops in rotation and allow for adoption of alternative nitrogen application, crop production, and irrigation technologies. Once field data is obtained, a sensitivity analysis should be performed to determine the accuracy of the predicted values given by the Opus model.

\section{Literature Cited}

Christensen, Lee A. 1999. An Assessment of the Economic and Environmental Potentials of New and Innovative Manure Management Technologies. Paper presented at the Southern Agricultural Economics Association meetings, Memphis, TN, February 1-3, 1999.

Copeland, C., and J. Zinn. 1998. Animal waste management and the environment: background for current issues. Congressional Research Service: 98-45I. May 12, 1998

Haan, C.T., B.J. Barfield, and J.C. Hayes. 1994. Design hydrology and sedimentology for sinall catchments. New York. Academic Press, Inc.

Leonard, R.A., W.G. Knisel, and D.A. Still. 1987. GLEAMS: Groundwater Loading Effects of Agricultural Management Systems. Transaction of the ASAE 30 (5): 1403-1418 https://doi.org/10.13031/2013.30578

McIntosh, J.E. 1988. "Erodibility and Sediment Yield by Natural Rainfall Events from Reconstructed Topsoil, Subsoil, and Mine Spoil." M.S. thesis, University of Kentucky.

Pierson, F.B., G.N. Flerchinger, and J.R. Wight. 1992. Simulating near-surface soil temperature and water on sagebrush rangelands: A comparison of models. https : / / ditiansatidip of the3ASACE 352(5):5 D449-1455

Richards, L.A. 1931. Capillary conduction of liquids in porous mediums. Physics 1: $318-333$

https://doi.org/10.1063/1.1745010

Richardson, C.S. 1981. Stochastic simulation of daily precipitation, temperature, and solar radiation. Water Resources Research 17: $.182-190$

https://doi.org/10.1029/WR017i001p00182

Ritchie, J.T. 1972. A model for predicting evaporation from a row crop with incomplete cover. Water Resources Research 8: 1204-1213

https://doi.org/10.1029/WR008i005p01204

Shaffer, M.J. and W.E. Larson. 1987. NTRM, a soil-crop simulation model for nitrogen, tillage, and crop-residue management. USDA. Conservation Research Rept. 34-1, $103 \mathrm{pp}$

Sharpley, A.N. and J.R. Williams, eds. 1990. EPIC Erosion/productivity Impact Calculator: 1. Model documentation. Tech. Bull. 1768. Washington, D.C.: USDA-ARS

Smith, R.E. 1992. Opus, an integrated Simulation inodel for transport of nonpoint-source pollutants at the field scale: Volume I, Documentation. United States Department of Agriculture, Agricultural Research Services, ARS-98. $120 \mathrm{pp}$

Smith, R.E. and V.A. Ferreira. 1989. Comparative evaluation of unsaturated flow methods in selected USDA simulation models. In H.J. Morel-Seytoux, ed., Unsaturated flow in hydrologic modeling theory and practices. Pp 391-412. North Atlantic Treaty Organization. ASl series C, vol 275. Dordrecgt. The Netherlands

Smith, R.E. and J.Y. Parlange. 1978. A parameter efficient infiltration model. Water Resources Research 14 (3): 533-538

https://doi.org/10.1029/WR014i003p00533

Smith, R.E. and J.R. Williams. 1980. Simulation of the water hydrology, chapter 2 . In CREAMS, a field scale model for Chemical, Runoff, and Erosion from Agricultural Management Systems. Vol. 1, pp. 13-35. USDA. Conservation Research report No. 26

Ward, A.D. 1981. "Characterizing Infiltration Through Reconstructed Surface Mine Profiles." Ph.D. dissertation, University of Kentucky. 
Williams, J.R. and H.D. Berndt. 1977. Sediment yield prediction based on watershed hydrology. Transaction of the ASAE 20: https: / / doi. org/10.11043031/2013.35710

Williams, J.R., P.T. Dyke, W.W. Fuchs, V.W. Benson, O.W. Rice, and E.D. Taylor. 1990. EPIC Erosion/productivity Impact Calculator: 2. User Manual. Tech. Bull. 1768. Washington, D.C.: USDA-ARS 